\title{
Implante em aorta abdominal de suíno de artéria pulmonar heteróloga conservada em glicerina
}

\author{
Replacement of porcine abdominal aorta using pulmonary artery heterograft \\ Simone Tostes de Oliveira ${ }^{1}$ Alceu Gaspar Raiser ${ }^{2}$ Carlos Afonso Castro Beck ${ }^{3}$ \\ Emerson Antônio Contesini ${ }^{3}$ Anderson Favero Cunha $^{4}$ Viviane Mara Woehl $^{5}$ \\ Rafael Stedile $^{6}$ Lederson Trindade de Lima $^{7}$
}

\begin{abstract}
A correção cirúrgica de várias doenças vasculares requer a implantação de próteses. Neste estudo, foi avaliado o comportamento da artéria pulmonar de cão conservada em glicerina a $98 \%$ implantada na aorta abdominal de dois suínos, acompanhados por cinco meses de pós-operatório. Ao exame macroscópico, um dos implantes apresentou dilatação e o outro estenose, em relação à aorta adjacente. Microscopicamente, o tecido hospedeiro e o implante estavam íntegros e a cicatrização se apresentou adequada. Apesar das diferenças de diâmetro encontradas (estenose e dilatação), ambos os animais tiveram desenvolvimento normal e não demonstraram problemas clínicos.
\end{abstract}

Palavras-chave: cirurgia vascular, implante, biomateriais, suínos.

\section{ABSTRACT}

This study evaluated the behavior of glycerin preserving canine pulmonary artery implanted in the abdominal aorta of two piglets, followed up for a period of five months postoperatively. Autopsy examination showed dilatation of one graft and stenosis of the other, compared to the aorta near the anastomosis site, and microscopic examination showed integrity of the host site and graft. There was satisfactory healing. Besides the differences between the implants (stenosis $x$ dilatation), both pigs presented normal growing, with no clinical problem.

Key words: vascular surgery, graft, biomaterials, piglets.
O suíno é particularmente útil no estudo de cirurgias vasculares, por apresentar crescimento rápido e por seu sistema cardiovascular ter semelhança anatômica com o humano (SCHOOF et al., 1998).

Os enxertos autólogos apresentam a vantagem de acompanhar o crescimento do hospedeiro, porém nem sempre estão disponíveis. Também prolongam o tempo operatório e causam lesão no sítio doador. O enxerto vascular mais amplamente utilizado e com melhores resultados é a veia autóloga a fresco. A despeito de sua ampla aceitação, as veias autólogas sofrem alterações morfológicas quando utilizadas como substitutos arteriais, relacionadas à perda da viabilidade endotelial durante a coleta e a implantação (LITWAK, 1998).

Em um estudo comparativo da viabilidade e morfologia das artérias aorta e pulmonar conservadas em solução de antibiótico-nutriente, LIVI et al. (1987) verificaram que a artéria pulmonar continha menor quantidade de tecido elástico e de cálcio total, tornando-a menos susceptível à calcificação que a artéria aorta. Os implantes homólogos de aorta calcificam-se mais rapidamente e em maior grau que

\footnotetext{
${ }^{1}$ Médico Veterinário, Mestre, Professor Substituto, Faculdade de Veterinária, Universidade Federal do Rio Grande do Sul (UFRGS), Av. Bento Gonçalves, 9090, Bairro Agronomia, 91540-000, Porto Alegre, RS. Autor para correspondência. E-mail: simonetostes@ bol.com.br. ${ }^{2}$ Médico Veterinário, Professor Titular Doutor, Universidade Federal de Santa Maria (UFSM).

${ }^{3}$ Médico Veterinário, Professor Doutor, UFRGS.

${ }^{4}$ Médico Veterinário, Mestre.

${ }^{5}$ Médico Veterinário, Professor Doutor, Universidade Federal de Santa Catarina (UFSC).

${ }^{6}$ Médico Veterinário, Residente, UFRGS.

${ }^{7}$ Acadêmico do Curso de Medicina Veterinária, UFSM.
} 
os homólogos de artéria pulmonar em poucos meses da sua implantação (MOLINA et al., 1989).

CLARKE et al. (1993) citaram que o mecanismo em potencial para a falência de enxerto homólogo é a resposta imunológica do hospedeiro. RAISER et al. (2000) implantaram artéria carótida homóloga na artéria femoral de cães conservada em glicerina, e o implante permaneceu pérvio e sem sinais de rejeição.

O objetivo deste experimento foi observar o comportamento da artéria pulmonar de cão conservada em glicerina como conduto biológico na aorta abdominal de suíno, visto que a mesma apresenta comportamento diferente de outros tecidos, devido ao alto gradiente de pressão exercido pelo sangue em seu interior.

Foram utilizados dois suínos fêmeas, com 2,5 meses de idade, raça Landrace $x$ Large White. Através de incisão pré-retroumbilical na linha média e com afastamento de alças intestinais, expôs-se a aorta abdominal que foi cuidadosamente dissecada do peritônio e clampeada imediatamente caudal à emergência das artérias renais e cranial à bifurcação das artérias ilíacas, com dois clampes vasculares. Fezse secção transversal, sendo as extremidades irrigadas com solução heparinizada, e um segmento de artéria pulmonar de cão, conservada em glicerina por um período mínimo de 30 dias, medindo $1,5 \mathrm{~cm}$, foi suturado às extremidades, com fio de polipropileno 5-0 através de sutura simples contínua. Após o término $\mathrm{da}$ anastomose, as pinças foram retiradas e o fluxo normal do sangue foi observado. No caso de pequenas hemorragias, foi realizada compressão digital local com gaze por cinco minutos. O peritônio foi suturado para minimizar possíveis aderências do vaso às vísceras, as alças intestinais foram reposicionadas e a cavidade abdominal fechada.

Os animais foram observados por cinco meses, atingindo pesos de 118 e $120 \mathrm{~kg}$, quando foram abatidos. Fez-se estudo macroscópico dos enxertos e o material foi coletado e fixado em formol a $10 \%$, desidratado em álcool e incluído em paraplast para microtomia. Cortes seriados de $5 \mathrm{~mm}$ de espessura foram corados com hematoxilina-eosina, para análise ao microscópico óptico. O crescimento dos suínos acompanhou a média esperada em relação a outros da mesma idade sob mesmas condições.
Macroscopicamente, ambos os implantes apresentavam-se íntegros, porém um dilatado e o outro estenosado, e nesse último não foi notada neovascularização colateral para compensar o fluxo sanguíneo da região.

Pela avaliação microscópica, verificou-se que tanto o tecido hospedeiro quanto o implante estavam íntegros e o endotélio e a camada muscular sem danos. O implante possuía maior quantidade de ramificações vasculares em relação à aorta, e estas estavam íntegras. Não houve sinais de calcificação do implante, uma das principais complicações que pode ocorrer nos primeiros meses, conforme MOLINA et al. (1989). Na região da sutura, observou-se a presença de infiltrado linfocitário e macrofágico, indicando reação inflamatória crônica. A cicatrização da sutura vascular se mostrou adequada, com presença de macrófagos. Não foram evidenciados sinais histológicos de rejeição a qual, segundo CLARKE et al. (1993), é a principal causa de falha de enxertos heterólogos. Possivelmente devido aos efeitos moduladores da glicerina como meio de conservação e controle da antigenicidade.

\section{REFERÊNCIAS BIBLIOGRÁFICAS}

CLARKE, D.R. et al. Degeneration of aortic valve allografts in young recipients. Journal of Thoracic and Cardiovascular Surgery, Philadelphia, v.105, n.5, p.934-942, 1993.

LITWAK, P. Princípios de cirurgia vascular. In: SLATTER, D. Manual de cirurgia de pequenos animais. 2.ed. São Paulo : Manole, 1998. V.1, cap.59, p.1070-1074.

LIVI, U. et al. Viability and morphology of aortic and pulmonary homografts. A comparative study. Journal of Thoracic and Cardiovascular Surgery, Philadelphia, v.93, n.5, p.755-760, 1987.

MOLINA, J.E. et al. Growth of fresh-frozen pulmonary allograft conduit in growing lambs. Circulation, Houston, part I, v.80, n.3, p.183-190, 1989.

RAISER, A.G. et al. Implantação de homoenxerto heterotópico na artéria femoral de cães. Arq Bras Med vet Zoot, Belo Horizonte, v.52, n.3, p.222-229, 2000.

SCHOOF, P.H. et al. Disproportionate enlargment of the pulmonary autrograft in the aortic position in the growing pig. Journal of Thoracic and Cardiovascular Surgery, Philadelphia, v. 115 , n. 6 , p. $1264-1272,1987$. 